\title{
A Cross Sectional Survey on Prevalence Rate and Physical Therapy Awareness of Cerebral Palsy in Panipat City
}

\author{
Kanika Bhaskar, Shefali Kapoor, Jyoti and Vinay Jagga
}

\begin{abstract}
Aim: This cross-sectional study assessed prevalence rate and physical therapy awareness of cerebral palsy (CP) in Panipat city. Method: A total two hundred (107 male and 93 female) of age between 2 to 7 year subject with premature birth $(<36$ weeks) and low birth weight $(<2500 \mathrm{~g})$ participated in the study. A structured questionnaire which sought information on socio- demographics, gestational age, birth weight, mother history, neonatal history, MAS and DTR scale was used to obtain data from the respondents who were taken from all government and private hospitals/ nursing homes having obstetrics and gynaecology department. Result: More than one fourth of the respondents, 54 (27\%) reported diagnosis was cerebral palsy hence $27.0 \%$ is reported prevalence rate and $42.6 \%$ was aware of physical therapy importance in cerebral palsy. There were significant associations between gestational age and low birth weight. A significant association was also found between delayed cry and birth asphyxia and cerebral palsy. Conclusion: It was concluded from the results of the present study that there was a high prevalence rate of CP and low physical therapy awareness in Panipat city. It was also found that cerebral palsy was significantly influenced by prematurity and low birth weight.
\end{abstract}

Kanika Bhaskar, Shefali Kapoor, Jyoti and Vinay

Jagga

E-mail:kanikabhaskar4@gmail.com

Prem Physiotherapy and Rehabilitation College

Panipat(Haryana) India
Key Words: Physical Therapy, Cerebral Palsy,Gestational, MAS, DTR

DOI: $10.18376 / j e s p / 2016 / v 12 / i 2 / 111263$

\section{Introduction}

Cerebral palsy (CP) describes a group of permanent disorders of the development of movement and posture, causing activity limitation that is attributed to non-progressive disturbances that occurred in the developing fetal or infant brain (Zeljka et al 2011). The motor disorders of cerebral palsy are often accompanied by disturbances of sensation, perception, cognition, communication and behavior by epilepsy, and by secondary musculoskeletal problems (Hwang et al 2011). Cerebral palsy is a static neurologic condition resulting from brain injury that occurs before cerebral development is complete. Because brain development continues during the first two years of life, cerebral palsy can result from brain injury occurring during the prenatal, perinatal, or postnatal periods (Bass 1999). The CP encompasses a spectrum of motor disorders of varying tone, anatomical distribution and severity. According to clinical classification $\mathrm{CP}$ is divided into Spastic, Dyskinetic, Hypotonic/Ataxic and Mixed type of CP. On the other hand CP is divided into Hemiplegia, Diplegia, Quadriplegia, Triplegia, Monoplegia and Double Hemiplegia on the basis of anatomical classification (Nadire 1999). Upper motor neuron 


\section{Journal of Exercise Science \& Physiotherapy, Vol. 12, No. 2, 2016 ISSN: 0973-2020 (Print) \\ ISSN: 2454-6089 (Online)}

syndrome often leads to common patterns of motor dysfunction and characteristic spasticity and contractures (Mayer et al 1997). Selective dorsal rhizotomy is a procedure intended to minimize or eliminate spasticity by selectively cutting dorsal rootlets from spinal cord segments L1 to S2. Postoperatively, it can create proprioceptive loss, bladder or bowel dysfunction, prolonged marked hypotonia, persistent back pain or spinal deformities (McLaughlin etal2002). Adequate knowledge of a disease condition has been reported to influence the patient's attitude and practice in the management of their illness and improving physical therapy awareness is known to improve compliance with treatment in CP. Therefore the present study assessed prevalence rate and physical therapy awareness in Panipat city (Haryana) India.

\section{Materials and methods}

This cross-sectional study recruited two hundred (107 male and 93 female) subject with premature birth and low birth weight. The selected hospitals were all government and private hospitals/ nursing homes having obstetrics and gynaecology department etc. The inclusion criteria for participation in the study involved low birth weight $(<2500 \mathrm{~g})$ and premature birth ( $<36$ weeks) of $2-7$ year of age, Rh incompatibility and birth asphyxia. Subjects were excluded if presented or reported any trauma after birth, genetic abnormality and age less than 2 years. Ethical approval was obtained from the Prem Physical Therapy and Rehabilitation College. Permission to conduct study was obtained from government and private hospitals/ nursing homes of Panipat city which provide us the history of children delivered in the hospital. Each respondent gave informed consent to participate in the study. Parents of subject were contacted and asked for the informed consent and a detailed questionnaire specifying cerebral palsy was filled by the same. We have used MAS and DTR scale as an assessment tool. Reflex hammer used to elicit the DTR. Subject who were not aware of the importance of physical therapy interventions, we were told them the importance for the purpose of awareness and better quality of life of subjects. The questionnaire used in the study was developed by a panel of experts. The questionnaire sought information on socio- demographics, gestational age, birth weight, mother history, neonatal history, MAS and DTR scale. The questionnaire was tested for reliability was determined in a pilot study among 20 subjects with prematurity and low birth weight. Consequently, items on the questionnaire that were ambiguous or extraneous were either modified or expunged. The internal consistency of the questionnaire was found to be 0.89 on Cronbach 's alpha. The answering options were - Yes or No. A correct response was assigned score of 1, incorrect response was given a score of 0. Data were summarized using descriptive statistics of mean, standard deviation, frequency and percentage. Inferential statistics of Chi Square test was used to determine associations among gestational age, birth weight, birth asphyxia, delayed cry, place of delivery, $\mathrm{Rh}$ incompatibility and mother history of disease. 


\section{Result}

The mean age of the respondents in this study was $4.51 \pm 1.70$ years (Table 1 ). The study recruited higher prevalence $27.0 \%$ of $\mathrm{CP}$ with prematurity and low birth weight and low physical therapy awareness $(42.6 \%)$. The $80.0 \%$ had reported delayed cry and $76.1 \%$ had birth asphyxia in influenced respondents. The $38.0 \%$ had CP who had taken birth in government hospitals while $16.0 \%$ have in case of private hospitals.

Table 1. Distribution of children according to age, birth weight and gestational age

\begin{tabular}{lll}
\hline Age & Mean \pm SD & $4.51 \pm 1.70$ \\
& Range & $2-7$ \\
Birth weight $($ Kg) & Mean \pm SD & $1.99 \pm .30$ \\
\multirow{2}{*}{ Gestational age(weeks) } & Range & $<2.5$ \\
& Mean \pm SD & $34.92 \pm 1.49$ \\
\hline
\end{tabular}

Table 2. Distribution of children according to history of disease, infection during pregnancy and accidental history

\begin{tabular}{|c|c|c|c|c|}
\hline & & \multirow{2}{*}{$\begin{array}{c}\text { Normal } \\
\text { Frequency }(\%)\end{array}$} & \multirow{2}{*}{$\begin{array}{l}\text { Cerebral palsy } \\
\text { Frequency }(\%)\end{array}$} & \multirow{2}{*}{\begin{tabular}{|c|} 
Other \\
Frequency $(\%)$
\end{tabular}} \\
\hline & & & & \\
\hline During pregnancy any & High BP & $25(54.3 \%)$ & $18(39.1 \%)$ & $3(6.5 \%)$ \\
\hline \multirow[t]{4}{*}{ history of disease } & Low BP & $18(56.2 \%)$ & $14(43.8 \%)$ & $0(\mathbf{0 . 0 \%})$ \\
\hline & Anaemia & $75(55.1 \%)$ & $51(37.5 \%)$ & $10(7.4 \%)$ \\
\hline & Diabetes & $20(100.0 \%)$ & $0(0.0 \%)$ & $0(0.0 \%)$ \\
\hline & Any other & $14(56.0 \%)$ & $11(44.0 \%)$ & $0(0.0 \%)$ \\
\hline During pregnancy any & Syphilis & $17(40.5 \%)$ & $20(47.6 \%)$ & $5(11.9 \%)$ \\
\hline \multirow[t]{2}{*}{ history of infection } & Torch & $18(58.1 \%)$ & $13(41.9 \%)$ & $0(0.0 \%)$ \\
\hline & Any other & $4(40.0 \%)$ & $4(40.0 \%)$ & $2(20.0 \%)$ \\
\hline $\begin{array}{l}\text { Accidental history } \\
\text { during pregnancy }\end{array}$ & Yes & $6(25.0 \%)$ & $15(62.5 \%)$ & $3(12.5 \%)$ \\
\hline
\end{tabular}

Table 3. Distribution of children with cerebral palsy according to sex, age, birth weight, gestational age, place of delivery, consanguineous marriage, $\mathbf{R h}$ incompatibility, multiple pregnancy, birth asphyxia and delayed cry

\begin{tabular}{|c|c|c|c|c|}
\hline & & Normal & $\begin{array}{c}\text { Cerebral } \\
\text { palsy }\end{array}$ & Other \\
\hline & & $\begin{array}{c}\text { Frequency } \\
(\%)\end{array}$ & $\begin{array}{c}\text { Frequency } \\
(\%)\end{array}$ & $\begin{array}{c}\text { Frequency } \\
(\%)\end{array}$ \\
\hline \multirow{3}{*}{ Sex } & Male & $69(64.5 \%)$ & $30(28.0 \%)$ & $8(7.5 \%)$ \\
\hline & Female & $67(72.0 \%)$ & $24(25.8 \%)$ & $2(2.2 \%)$ \\
\hline & $\leq 3$ & $45(68.2 \%)$ & $19(28.8 \%)$ & $2(3.0 \%)$ \\
\hline \multirow[t]{2}{*}{ Age } & $4-5$ & $45(67.2 \%)$ & $19(28.4 \%)$ & $3(4.5 \%)$ \\
\hline & $\geq 6$ & $46(68.7 \%)$ & $16(23.9 \%)$ & $5(7.5 \%)$ \\
\hline \multirow{2}{*}{ Birth weight } & $\leq 1.86$ & $19(30.2 \%)$ & $39(61.9 \%)$ & $5(7.9 \%)$ \\
\hline & $\geq 1.87$ & $117(85.4 \%)$ & $15(10.9 \%)$ & $5(3.6 \%)$ \\
\hline
\end{tabular}




\begin{tabular}{|c|c|c|c|c|}
\hline \multirow{2}{*}{ Gestational age } & $\leq \mathbf{3 4}$ & $20(29.9 \%)$ & $43(64.2 \%)$ & $4(6.0 \%)$ \\
\hline & $\geq 34$ & $116(87.2 \%)$ & $11(8.3 \%)$ & $6(4.5 \%)$ \\
\hline \multirow[t]{2}{*}{ Place of delivery } & Government & $57(58.2 \%)$ & $38(38.0 \%)$ & $5(5.1 \%)$ \\
\hline & Private & $79(77.5 \%)$ & $16(16.0 \%)$ & $5(4.9 \%)$ \\
\hline $\begin{array}{l}\text { Consanguineous } \\
\text { marriage }\end{array}$ & Yes & $5(27.8 \%)$ & $11(61.1 \%)$ & $2(11.1 \%)$ \\
\hline Rh incompatibility & Yes & $5(16.1 \%)$ & $24(77.4 \%)$ & $2(6.5 \%)$ \\
\hline Multiple pregnancy & Yes & $24(60.0 \%)$ & $14(35.0 \%)$ & $2(5.0 \%)$ \\
\hline Birth asphyxia & Yes & $6(9.0 \%)$ & $51(76.1 \%)$ & $10(14.9 \%)$ \\
\hline Delayed cry & Yes & $4(6.2 \%)$ & $52(80.0 \%)$ & $9(13.8 \%)$ \\
\hline
\end{tabular}

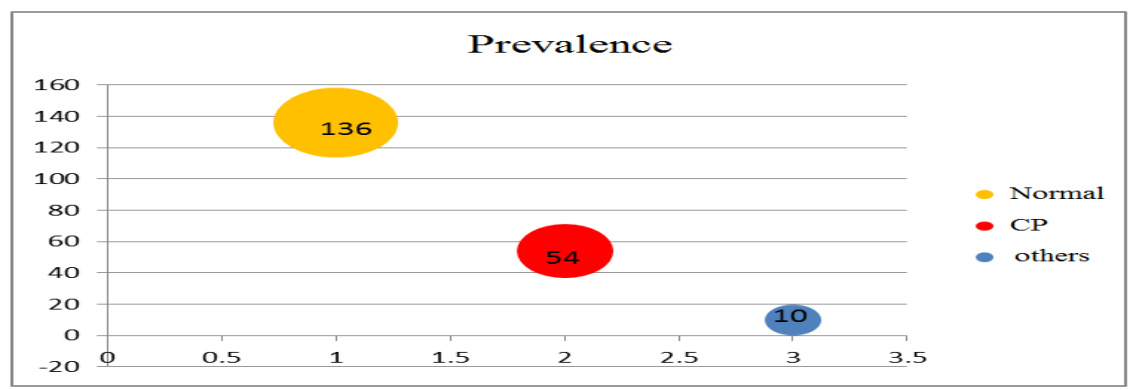

Figure 1. Frequency of Prevalence rate of cerebral palsy

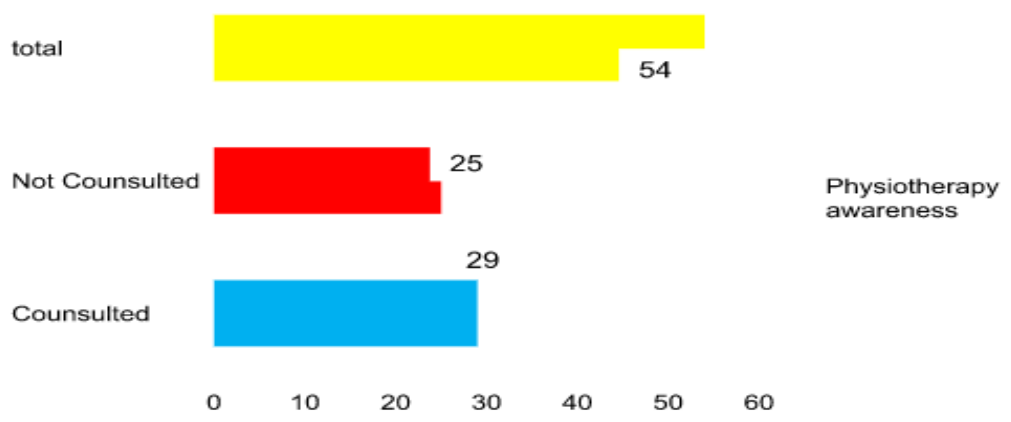

Figure 2. Frequency of physical therapy awareness

Respondents, who had received treatment from physiotherapist, were less than half i.e. $20.3 \%$. Two cases of Autism, two cases of deaf and dumb, three cases of MR, three cases of western syndrome, and seven cases of epilepsy was found in the present study. A majority of respondents (72\%) diagnosis is normal and $23.6 \%$ respondent's diagnosis is $\mathrm{CP}$ in consanguineous marriage group $\left(\mathrm{p}=0.000^{* *}\right)$. There was significant association between consanguineous marriage and $\mathrm{CP}$. A majority of respondents $(77.5 \%)$ diagnosis is normal and $17.8 \%$ respondent's diagnosis is $\mathrm{CP}$ and $4.7 \%$ others in Rh incompatibility group $\left(\mathrm{p}=0.000^{* *}\right)$. There was significant association between Rh incompatibility and CP. A majority of respondents $(80.0 \%)$ diagnosis is $\mathrm{CP}$ and $6.2 \%$ respondent's diagnosis is Normal in Delayed cry group $\left(\mathrm{p}=0.000^{* *}\right)$. A majority of respondents $(76.1 \%)$ 


\section{Journal of Exercise Science \& Physiotherapy, Vol. 12, No. 2, 2016 ISSN: 0973-2020 (Print) \\ ISSN: 2454-6089 (Online)}

diagnosis is $\mathrm{CP}$ and $9 \%$ respondents diagnosis is Normal in Birth asphyxia group is $(\mathrm{p}=$ $\left.0.000^{* *}\right)$. There was significant association between birth asphyxia and CP. A majority of respondents $(44.7 \%)$ diagnosis is $\mathrm{CP}$ in jaundice group. There was significant association between jaundice and $\mathrm{CP}\left(\mathrm{p}=0.000^{* *}\right)$. In Gestational age group $\leq 34$, majority of respondents $(64.2 \%)$ diagnosis is CP. But in case of Gestational age group "> 34 ", majority of respondents $(87.2 \%)$ diagnosis is normal. $(\mathrm{p}=0.000)$. There was significant association between gestational age and CP. In case of birth weight group " $\leq 1.86$ ", majority of respondents (61.9\%) diagnosis is CP. While in case of birth weight group "> 1.86 ", majority of $85.4 \%$ of respondent's diagnosis is normal $(\mathrm{p}=0.000)$. There was significant association between birth weight and CP.

\section{Discussion}

The results of the present study show that there was a high prevalence rate of $\mathrm{CP}$ and low physical therapy awareness in Panipat city. Maryam et al. (2013) reported the prevalence of CP expressed by gestational age was highest in children born before 28 weeks' gestation (111.80 per 1000 live births; 95\% CI 69.53-179.78; p<0.0327). Yudkin and Johnson (1995) investigated the risk of cerebral palsy following intrapartum asphyxia at term, and the contribution of intrapartum asphyxia at term to the overall rate of cerebral palsy and recognized that the initial hypoxial insult might have occurred in the antenatal period. Vandana et al (2014) also supported the results of the present study that a disability is restriction or lack of ability to perform an activity in a manner or within the range considered normal for a human being. The prevalence of disability is 7 per 1000 live births in India. 20\% are not aware about the legal issues for person with disability in developing countries. Kyllerman et al. (1982) reported that hyperbilirubinemia was present as a contributory factor in $32 \%$. Following the development of safe routines for testing and treatment, hyperbilirubinemia has almost disappeared as a risk factor in Sweden. The subgroup of children born preterm, who are more vulnerable to hyperbilirubinemia than those born at term, had decreased from $35 \%$ to $19 \%$ in the present one. There are certain limitations addressed during the present research study like some hospitals did not have their records maintained and others had the records but without any proper documentation i.e. contact number and address of the patients etc. Some hospitals did not maintain maternal screening records properly and proper neonatal examination records were also not present. In 70\%-80\% of cases Apgar scoring was not found in records, which is one of the main markers of CP.

\section{Clinical Implication of findings}

Maternity care must continue to focus on antenatal risk factors so that pregnancies with risk associated with cerebral palsy can be identified and managed appropriately; Efforts must continue to prevent low birth weight and preterm births and where they are inevitable to provide antenatal and neonatal interventions to reduce associated risk factors of CP.Multiple births should continue to be the subject of close surveillance in an effort to reduce the associated mortality and morbidity, particularly cerebral palsy; Due to its association with cerebral palsy, delayed child bearing and the transfer of multiple embryos with fertility treatment must be addressed through education and policy initiatives. Doctor should aware the patient for regular developmental assessment and regular check-up if there is any birth defect noticed at the birth of child. 


\section{Journal of Exercise Science \& Physiotherapy, Vol. 12, No. 2, 2016 ISSN: 0973-2020 (Print) \\ ISSN: 2454-6089 (Online)}

\section{Conclusion}

It was concluded from the results of the present study that there was a high prevalence rate of $\mathrm{CP}$ and low physical therapy awareness in Panipat city. It was also found that cerebral palsy was significantly influenced by prematurity and low birth weight. Most of the patients who have consulted a physiotherapist, were not taking physical therapy treatment because of long duration of treatment, financial problems and unsatisfactory outcome of the physical therapy treatment. We had motivated parents as well as the society. The results of the present study suggest that we can plan some awareness campaigns about $\mathrm{CP}$ and the role of Physical therapy in its treatment which will help people gain the required information about the disease. Also, time to time camps those offer free diagnosis can help as some of the people face financial problems and do not even get to have a check-up.

\section{Acknowledgement}

The authors wish to thank Mom and Dad you have supported and helped me along the course of this dissertation by giving encouragement and providing the moral and emotional support I needed to complete my thesis. To them, I am eternally grateful.

\section{References}

Bass N.1999. Cerebral palsy and neurodegenerative disease. Curr Opin Pediatr, 11:5047.

Butler C, Campbell S.2000.For the AACPDM Treatment Outcomes Committee Review Panel. Evidence of the effects of intrathecalbaclofen for spastic and dystonic cerebral palsy. Dev Med Children Neurol, 42:634-45.

Hwang, M., Kuroda, M.M., Tann, B., and Gaebler-Spira, D.J.2011. Measuring Care and Comfort in Children with Cerebral Palsy: The Care and Comfort Caregiver Questionnaire. The American Academy of Physical Medicine and Rehabilitation, 3 (10):912-919.

Kyllerman M. Dyskinetic Cerebral Palsy. II.1982.Pathogenetic risk factors and intrauterine growth. Acta Paediatr Scand, 71:551-558.

Maryam OskouiFranzinaCoutinho.2013. "An update on the prevalence of cerebral palsy: a systematic review and meta-analysis" 24th January 2013. Developmental Medicine \& Children Neurology.

Mayer N.H., Esquenazi A., and M.K.1997. Childreners: Common patterns of clinical motor dysfunction. Muscle Nerve Suppl, 20:S21-35.

McLaughlin J., Bjornson K., Temkin N., Steinbok P., Wright V., Reiner A., et al.2002.Selective dorsal rhizotomy: meta-analysis of three randomized controlled trials. Dev Med Children Neurol,44:17-25.

Nadire Berker and SelimYalçin "The Help Guide To Cerebral Palsy Second Edition" classification 2010 By MerillCorporationPage 12- 13.

Vandana J. Rathod, and Jagatheesan Alagesan.2014."Family Awareness Of Legislative Issues On Children With Cerebral Palsy: Cross Sectional Survey",International Journal of Physical Therapy and Research, $\mathrm{Vol}$ 2(3):511-17.

Yudkin P.L. and Johnson A. (1995). "Assessing the contribution of birth asphyxia to cerebral palsy in term singletons",.Journal of Paediatric and Perinatal Epidemiology,9(2):156-70.

Zeljka Petelin Gadze. 2011.Epilepsy in Children - Clinical and Social Aspects. Chapter14, page no 213 Published By InTech.

Conflict of Interest: None Declared 